\title{
Psicooncología
}

ISSN: $1696-7240$

http://dx.doi.org/10.5209/PSIC.57094

\section{Película recomendada sobre cuidados paliativos}

No sé decir adiós. España 2017. Director Lino Escalera. Duración: 96'. Temas: enfermedad avanzada oncológica, deseos de paciente, actitudes diferenciadas de la familia ante la inclusión del paciente en cuidados paliativos, cambios en roles y dinámicas familiares, negación en una parte de la familia, manejo del deterioro progresivo y de la proximidad de la muerte.

Festival de Málaga Cine en español. Premio especial del Jurado, mejor guión, mejor actor de reparto (Juan Diego), y mejor actriz (Nathalie Poza)

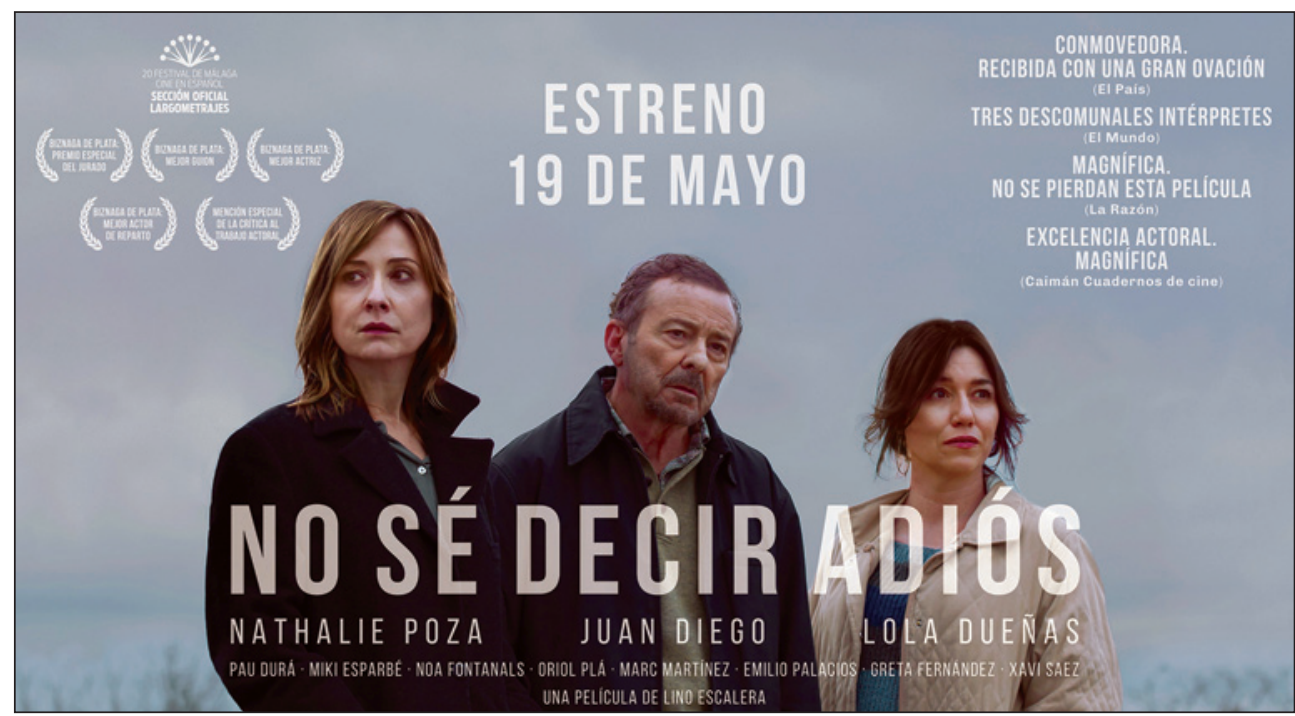

La película refleja lo que vemos de manera cotidiana los profesionales de cuidados paliativos, está planteada desde el momento en que al paciente se le indica que no hay tratamiento curativo para su enfermedad y se le sondea la posibilidad de recibir cuidados paliativos. El personaje interpretado como el padre, por Juan Diego es muy fiel a la realidad. Pero la historia está contada desde la perspectiva de la familia y cómo repercute en los diversos miembros de la familia, cuando hay una enfermedad grave, avanzada y con posibilidad de fallecimiento en un periodo limitado o relativamente corto en el tiempo.

Aunque el director es debutante, no por ello deja de plasmar de manera casi fotográfica lo que sucede cuando una enfermedad hace acto de presencia en una familia. Quizás hay algunas cuestiones que se plantearían de manera distinta, 
como el ofrecimiento de cuidados paliativos. Lo que sí se refleja es esa especie de "terremoto familiar" que se produce cuando una persona muy querida se encuentra muy enferma, piden tomar decisiones a la familia, y aparece el miedo a equivocarnos, que bloquea, y hace que se pospongan algunas decisiones.

Los temas que aborda la película están tratados con delicadeza, con ternura y con una buena dosis de humanidad. Se habla de la muerte sin nombrarla demasiado, indirectamente pero con la realidad por delante. Es como un triángulo equilátero en cuyos vértices están las dos hijas y el padre, y las interacciones que se producen entre cada diada (cada dos de ellos), como si fueran tres reencuentros en un lugar de uno global.

Se ve cómo se transforman los roles familiares, cómo cambian las relaciones padre -hijas, con cada una de las hijas y la relación entre ellas, a medida que se van desarrollando los acontecimientos y que la enfermedad evoluciona. Aparecen los conflictos familiares, la diferencia de criterios en cuanto al manejo del padre y cómo esto polariza mucho más, lo que se considera que es mejor para el paciente. Cuando ocurre esto, los familiares más cercanos (hijas en este caso) tienen que adaptar su vida a lo que está produciendo la enfermedad, dejar de trabajar, viajar a otra ciudad, vivir en casa de un familiar con quien no se está acostumbrado, pasar más tiempo con la persona enferma, arreglar cuestiones pendientes...

Una de las hijas, Carla, (el personaje que interpreta Nathalie Poza), muestra lo que nosotros describimos como "Síndrome del hijo de Bilbao", pero que en algunos lugares se le ha cambiado el nombre, el hijo de San Sebastián o el hijo de Burgos. Y aquí podría llamarse "síndrome de la hija de Barcelona". Es curioso cómo cambia el nombre de las cosas según donde estemos y nuestras concepciones personales y laborales-sanitarias. Esto nos plantea el tema también de las segundas opiniones ante enfermedades graves, de lo que implica para una persona enferma, de edad avanzada (en la película), con menos energía, tener que moverse y trasladarse a otra ciudad, para que le digan lo mismo o, como mucho, le planteen la inclusión en un ensayo clínico, lo cual influirá indudablemente en su calidad de vida.

Es curioso el efecto de la Negación de la realidad, cuando alguien se convence de "no ver para ver el resto de las cosas que están pasando", actuar con ellas, hasta el momento en que la persona se sienta preparada para "ver lo que no quiero ver". En la película se muestra como bloqueo emocional y al mismo tiempo como hiperacción (hacer algo sin importar si cumple el objetivo y es coherente). Es crearse una coraza-armadura para que algo de fuera no duela, pero no nos protege de nuestro dolor interno que sigue ahí, y al mismo tiempo la armadura impide la ayuda desde fuera, para aliviar ese dolor.

Blanca, la otra hija, interpretada por Lola Dueñas, mantiene una actitud de aceptación, que en algunos momentos roza la sumisión a las necesidades del padre y a las circunstancias, y en otros momentos actúa más motivada por minimizar el conflicto con su hermana, que sabe que es la persona, familiar próximo, que le va a quedar, cuando su padre fallezca. Es casi una cuestión de supervivencia, decidir llevarse bien con la hermana, por el bien de todos (presente y futuro), y al mismo tiempo lucha y se debate por tratar de transmitir a su incrédula hermana la realidad de lo que está pasando y como al final la realidad se va imponiendo, el padre va empeorando sin que se pueda hacer más por evitarlo. Blanca se sitúa más en la esfera de la realidad y Carla en la del deseo y la irrealidad, la fantasía incluso. 
Lo que provoca el inicio de la película no deja de ser una oportunidad para recuperar las relaciones perdidas, arreglar asuntos pendientes y curar heridas abiertas o mal cicatrizadas. Todo ante el abismo de la muerte que cada personaje interpreta de manera diferente. La sensación de vorágine y de vacío se extiende como los círculos concéntricos cuando se lanza una piedra en un estanque. El reencuentro del padre con las hijas (especialmente con la hija cuya relación estaba más deteriorada, en parte por la distancia), se produce en condiciones de vulnerabilidad de todas las partes. El miedo y el desconocimiento nos bloquean pero al mismo tiempo les sirven a los personajes como catapulta hacia un lugar que desconocen y con unas circunstancias con las que tienen que lidiar de la mejor manera posible.

Hay que reseñar la función del resto de los personajes secundarios, en la oficina, en el hospital y en los otros lugares, porque permiten acotar ambientes y resaltar emociones de los personajes principales. Devuelven a los personajes principales como un espejo algunas de las cosas que están pasando y que no terminan de ver.

La película habla de las despedidas (el título precisamente alude a ello), de nuestros miedos a despedirnos, de lo que nos aferramos a algunas cuestiones, ideas, creencias, percepciones, imágenes de una persona,... aunque estén equivocadas en ese momento porque la realidad ha evolucionado en otra dirección. Es relevante que a veces cuando salimos de la situación cotidiana, cuando la realidad se pone delante de nuestros ojos y somos conscientes de lo que sucede, nos vemos "desnudos ante el destino" es cuando realmente podemos decir adiós, con todo lo que implica.

Quienes trabajamos en cuidados paliativos sabemos de la importancia de la despedida, tanto en el paciente hacia sus seres queridos, de la familia hacia la persona que va a fallecer y la relación que tenían con ellos y también de los sanitarios hacia el paciente y la familia; por eso hacemos "cartas de condolencias", entre otras cosas; pero también nosotros necesitamos despedir-cerrar esa relación con paciente y familia que ha sido muy intensa, seguramente, y que normalmente nos aporta mucho y nos hace aprender sobre la vida. Gracias!!

La rabia, la ira (fundamentalmente en la hija Carla), la impotencia, el valor de pedir perdón o de reconocer un error, forman parte de las piezas de este puzle que compone la película, y muestra que todo está enlazado y que es interdependiente.

Todo esto, bien hecho, es el inicio del duelo; por eso es fundamental que se haga bien, porque sentamos las bases para que el duelo se pueda elaborar sólidamente, sobre "tierra firme" y no sobre arena o castillos en el aire. Nos habla también de nuestro afrontamiento de los aspectos anticipatorios del duelo y las anticipaciones que hacemos de cómo serán las cuestiones después de la muerte de la persona querida.

En la película, los paisajes que aparecen, que explora José Luis (el personaje de Juan Diego) con sus dos hijas, a veces sólo con una de ellas, forman parte de la experiencia que viven todos; y el paisaje que se muestra a través del viaje, es parte del acompañamiento y del apoyo que tienen los personajes. El viaje no deja de ser un trayecto hacia lo desconocido de la muerte. Ante el miedo que produce todo esto, se producen conductas de escape / evitación como manera de hacer frente a la realidad. Es como una "huida hacia delante". 
Convergen las dificultades de comunicación entre los diversos personajes, con las incertidumbres presentes y dificultades pasadas, y en parte con los miedos futuros sobre la posible o probable evolución.

El director indica que la frase que le acompañó en todo el proceso de realización de la película, es la frase con que comienza la película Tormenta de hielo, Ang Lee (1997), "La familia es el vacío desde donde emerges y el lugar donde regresas al morir". Lo cual es una excelente reflexión sobre la función de la familia y el ciclo de la vida.

Para conocer el mundo de los cuidados paliativos y las realidades que se producen en el día a día. Nos plantea muchas preguntas sobre la vida, la muerte, el afecto que sentimos por nuestros seres queridos y cómo abordamos nuestras emociones y las relaciones con las demás personas al final de la vida. 